\title{
Femtosecond laser and microkeratome-assisted Descemet stripping endothelial keratoplasty: first clinical results
}

\author{
Andreia Martins Rosa, ${ }^{1,2,3}$ Maria Fátima Silva, ${ }^{4}$ Maria João Quadrado, ${ }^{1,2,3}$ \\ Esmeralda Costa, ${ }^{1,3}$ Inês Marques, ${ }^{1}$ Joaquim Neto Murta ${ }^{1,2,3}$
}

${ }^{1}$ Ophthalmology Unit, Centro Hospitalar e Universitário de Coimbra, Coimbra, Portugal ${ }^{2}$ Centro Cirúrgico de Coimbra, Coimbra, Portugal

${ }^{3}$ Faculty of Medicine, University of Coimbra, Coimbra, Portugal ${ }^{4} V$ isual Neuroscience Laboratory, IBILI, Faculty of Medicine, University of Coimbra, Coimbra, Portugal

Correspondence to

Professor Joaquim Neto Murta, Ophthalmology Unit, Centro Hospitalar e Universitário de Coimbra, Praceta Mota Pinto, Coimbra 3049, Portugal; jmurta@netcabo.pt

Received 22 July 2012 Revised 7 February 2013 Accepted 23 February 2013
To cite: Rosa AM, Silva MF, Quadrado MJ, et al. Br J Ophthalmol Published Online First: [please include Day Month Year] doi:10.1136/bjophthalmol2012-302378

\section{ABSTRACT}

Aim To perform Descemet stripping automated endothelial keratoplasty (DSAEK) using a novel technique to obtain very thin $(<100 \mu \mathrm{m})$ posterior corneal disks. Methods Twenty five DSAEK grafts were prepared with two sequential cuts: the first cut, of variable thickness, was made with a femtosecond laser and the second with a $300 \mu \mathrm{m}$ microkeratome head. Spectacle corrected visual acuity, endothelial cell density evaluation with specular microscopy and anterior segment optical coherence tomography to measure central and peripheral graft thickness was performed preoperatively and postoperatively at 1, 3 and 6 months.

Results There were no irregular cuts or perforations during tissue preparation. Central graft thickness was $79.6 \mu \mathrm{m}(\mathrm{SD} \pm 14.5$; range 54-98) and $69.3 \mu \mathrm{m}$ $(S D \pm 14.2$; range 49-96) at 3 and 6 months. Corrected distance visual acuity improved from 0.91 logMAR preoperatively to $0.11 \log$ MAR at 6 months. Donor endothelial cells averaged 2675 cells $/ \mathrm{mm}^{2}$ preoperatively and 1729 cells $/ \mathrm{mm}^{2}$ at 6 months. There were no graft detachments.

Conclusions This new technique consistently yielded very thin grafts $(<100 \mu \mathrm{m})$, excellent visual acuity results and good endothelial cell counts. No donor tissue was wasted.

\section{INTRODUCTION}

Descemet stripping automated endothelial keratoplasty (DSAEK) has become the standard procedure for Fuchs dystrophy and other endothelial dysfunction disorders. ${ }^{1}$ DSAEK consists of stripping a patient's diseased endothelium and replacing it with healthy endothelium, Descemet's membrane and a layer of stroma prepared from a donor cornea with an automated microkeratome. ${ }^{2}{ }^{3}$

One limitation of DSAEK is that some eyes do not achieve good visual acuity despite a clear cornea and minimal residual astigmatism. This may be due to interface irregularity, the presence of donor posterior stroma or a thick endothelial graft. $^{4-6}$ The influence of endothelial graft thickness on visual acuity in DSAEK is controversial, with some authors reporting better results with thinner grafts and others finding no correlation. ${ }^{6-11}$ However, in studies where no correlation was found, grafts were relatively thick $(>160 \mu \mathrm{m}) \cdot{ }^{8-10}$ Indeed, in none of these studies was graft thickness less than $100 \mu \mathrm{m}$. The procedure to obtain thin grafts carries a higher risk of perforation. Our group has previously reported a technique that combines a femtosecond laser with a microkeratome to create grafts of less than $100 \mu \mathrm{m}$ in eye bank eyes (Murta et al, 2nd Eucornea Congress, 2011).

We present below the first clinical outcomes of DSAEK performed with this new approach.

\section{MATERIALS AND METHODS \\ Patients}

This prospective study comprised 25 eyes from 25 patients with Fuchs endothelial dystrophy (14 eyes) or pseudophakic bullous keratopathy (11 eyes). Exclusion criteria were coexisting non-corneal abnormalities, such as macular degeneration and advanced glaucoma, and history of previous corneal surgery or visually significant corneal scarring. There were no relevant coexisting systemic diseases. Institutional review board approval was obtained and patients were provided with informed consent after the possible consequences of participation had been explained.

\section{Surgical technique}

Donor corneas were obtained from Fondazione Banca Degli Occhi (Venice, Italy) preserved in organ culture medium at $31^{\circ} \mathrm{C}$. Each cornea was mounted on an artificial anterior chamber (ALTK, Moria SA, Antony, France) filled with balanced salt solution (BSS, Alcon, Fort Worth, Texas, USA). Central pachymetry was performed with an ultrasonic pachymeter (CorneoGage Plus $50 \mathrm{MHz}$; Sonogage, Cleveland, Ohio, USA) after removal of the epithelium. Five readings were averaged. The BSS bottle was elevated to $220 \mathrm{~cm}$ and the tubing clamped at $60 \mathrm{~cm}$ from the anterior chamber. Two cuts were made. An Intralase FS60 femtosecond laser (Abbott Medical Optics, Santa Ana, California, USA) was used for the first cut and a Moria CBm microkeratome with a $300 \mu \mathrm{m}$ cutting head was used for the second. The thickness of the first cut was calculated as follows:

Femtosecond cut thickness

$$
=\text { Corneal pachymetry }-410 \mu \mathrm{m}^{*}
$$

*This figure is the sum of the theoretical microkeratome cut thickness $(300 \mu \mathrm{m})$ plus the desired final graft thickness $(110 \mu \mathrm{m})$.

Femtosecond settings were full lamellar cut, diameter $9.5 \mathrm{~mm}$, raster energy $1.5 \mu \mathrm{J}$ and anterior side cut at $90^{\circ}$. No suction ring was used and docking was straightforward. The first anterior stromal lenticule was easily removed following the femtosecond cut. In no case was manual dissection 
needed. The second cut was performed immediately afterwards with the $300 \mu \mathrm{m}$ microkeratome head, keeping the manual rotation speed constant and with total duration of approximately $5 \mathrm{~s}$. The tubing was unclamped from the BSS bottle at $150 \mathrm{~cm}$.

Donor tissue was removed by gently pulling the scleral rim from the top of the anterior chamber and was transferred to an $8.5 \mathrm{~mm}$ Hessburg-Barron trephine (Katena Products, Denville, New Jersey, USA).

Recipient preparation and donor insertion were performed as previously described. ${ }^{12}$ In brief, the procedure consisted of stripping Descemet's membrane, performing an inferior iridectomy to prevent pupillary block, transferring the graft using a Busin glide (Moria SA) and filling the anterior chamber almost completely with air underneath the graft.

Seventeen patients were pseudophakic preoperatively. Concurrent cataract surgery was performed in eight cases, before the Descemet stripping. Surgeries were performed by one surgeon (JNM). Postoperative medication consisted of ofloxacin $3 \mathrm{mg} / \mathrm{ml}$ and dexamethasone $1 \mathrm{mg} / \mathrm{ml}$ six times a day for 2 weeks and then tapered according to clinical response.

\section{Outcome analysis}

Graft thickness was measured at 1, 3 and 6 months using anterior segment optical coherence tomography (Spectralis Anterior Segment Module, Heidelberg, Germany). The scanning line was positioned on the $180^{\circ}$ axis into the corneal vertex and measurements were taken at the vertex and at $3 \mathrm{~mm}$ on either side to obtain peripheral thickness (figure 1).

Corrected distance visual acuity (CDVA) with subjective refraction was recorded preoperatively and at 1,3 and 6 months after surgery. Baseline donor endothelial cell density (ECD) was provided by the eye bank and was measured postoperatively with specular microscopy (Tomey EM-3000, Nagoya, Japan).

Statistical analysis was performed with IBM SPSS Statistics V.19 (SPSS Inc, Chicago, USA). Repeated measures analysis of variance with Bonferroni correction for multiple comparisons was used after verifying that data did not significantly deviate from normal distribution (Kolmogorov-Smirnov test). All results with $\mathrm{p}<0.05$ were considered statistically significant.

\section{RESULTS}

A total of 25 patients (17 female and 8 male subjects) aged between 48 and 88 years (mean age $65.0 \pm 13.4$ years) were included. Average postoperative follow-up was 6 months (range 5-7 months). Tissue was prepared without perforations, irregular cuts or buttonholes.
Table 1 Central and peripheral DSAEK graft thickness measured with anterior segment OCT at 1, 3 and 6 months postoperatively

1 month $(n=25) \quad 3$ months $(n=25) \quad 6$ months $(n=23)$

\begin{tabular}{|c|c|c|c|}
\hline \multicolumn{4}{|c|}{ Central DSAEK graft thickness } \\
\hline Mean $\pm S D(\mu m)$ & $83.1 \pm 23.6$ & $79.6 \pm 14.5$ & $69.3 \pm 14.2$ \\
\hline Range ( $\mu \mathrm{m})$ & $53-127$ & $54-98$ & $49-96$ \\
\hline \multicolumn{4}{|c|}{ Peripheral DSAEK graft thickness } \\
\hline Mean \pm SD $(\mu \mathrm{m})$ & $107.5 \pm 26.2$ & $104.5 \pm 32.3$ & $105.3 \pm 29.7$ \\
\hline
\end{tabular}

Peripheral thickness was obtained as the average of values obtained at $3 \mathrm{~mm}$ either side of the vertex of the cornea.

DSAEK, Descemet stripping automated endothelial keratoplasty; OCT, optical

coherence tomography.

Central preoperative donor corneal thickness after epithelium removal was $542.4 \mu \mathrm{m}$ (range: 505-600 $\mu \mathrm{m}$ ). Central graft thickness decreased continuously from $83.1 \mu \mathrm{m}$ at the first month to 79.6 and $69.3 \mu \mathrm{m}$ at 3 and 6 months (table 1 and figure 2).

Multiple comparisons showed statistically significant differences between the first and sixth month central graft thickness and between the third and sixth month central graft thickness $\left(\mathrm{F}_{(2,44)}=21.39 ; \mathrm{p}<0.001 ; \eta_{\mathrm{p}}^{2}=0.493, \mathrm{p}<0.001\right.$ in both comparisons). The same analysis was performed for peripheral DSAEK graft thickness but the differences were not significant $\left(\mathrm{F}_{(2,44)}=0.189 ; \mathrm{p}=0.828 ; \eta_{\mathrm{p}}^{2}=0.009\right)$.

The linear Pearson correlation coefficient was used to evaluate the relationship between the obtained graft thickness and the original donor corneal thickness. No statistically significant correlation was found at any time point $\left(1\right.$ month: $r_{\text {Pearson }}=-0.39$, $\mathrm{p}=0.33 ; 3$ months: $\mathrm{r}_{\text {Pearson }}=-0.54, \mathrm{p}=0.17$ and for 6 months: $\mathrm{r}_{\text {Pearson }}=-0.69, \mathrm{p}=0.13$ ).

CDVA continuously improved from $0.91 \log$ MAR preoperatively to 0.15 and $0.11 \log$ MAR at 3 and 6 months postoperative (table 2 and figure 2). Statistically significant differences were found for CDVA between preoperative and at 3 and 6 months $\left(F_{(2,42)}=11.41 ; p=0.015 ; \eta_{p}^{2}=0.65 ; p=0.017\right.$ and $\mathrm{p}=0.013$, respectively, multiple comparisons). No differences in CDVA were found between 3 and 6 months postoperatively $(p=0.56)$. At 3 and 6 months, $60.0 \%$ and $85.7 \%$ of eyes achieved CDVA of $20 / 30$ or more. CDVA was $20 / 20$ in $10 \%$ of eyes at 3 months and $14.3 \%$ at 6 months. Spherical equivalent increased from $-1.31 \mathrm{D}$ preoperatively to $-0.7 \mathrm{D}$ at 6 months.

Average precut ECD was 2675 cells $/ \mathrm{mm}^{2}(\mathrm{SD} \pm 251)$ and 1729 cells $/ \mathrm{mm}^{2}(\mathrm{SD} \pm 296)$ at 6 months, representing a $35.4 \%$ cell loss (table 2). There was a main effect for ECD

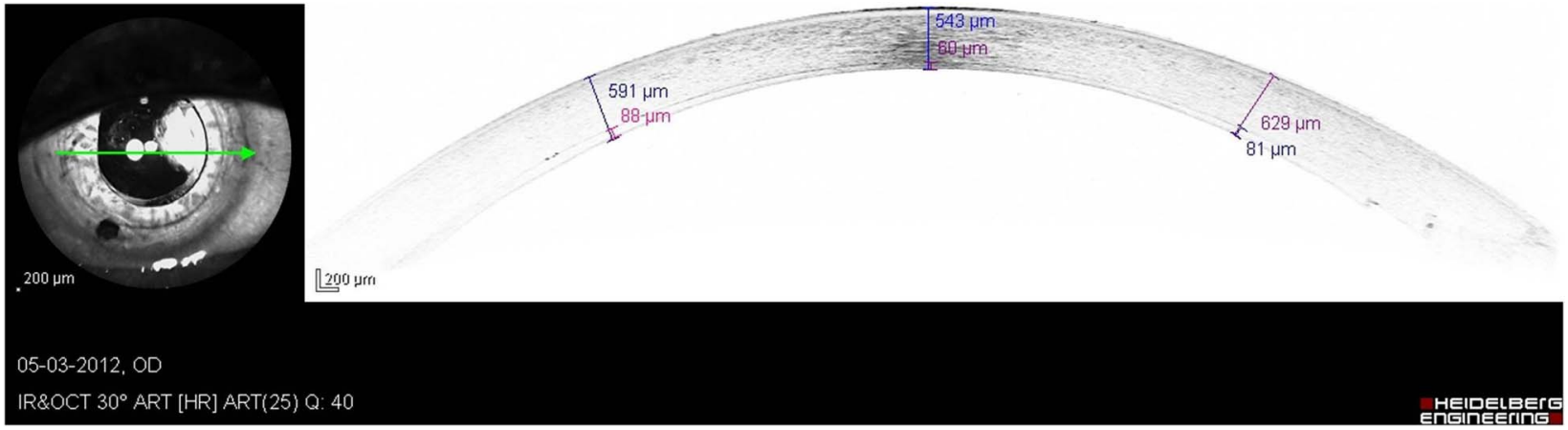

Figure 1 Anterior segment optical coherence tomography performed 1 month after Descemet stripping automated endothelial keratoplasty (femtosecond and microkeratome assisted) showing a posterior lamellar graft with a central thickness of $60 \mu \mathrm{m}$, temporal thickness of $88 \mu \mathrm{m}$ and nasal thickness of $81 \mu \mathrm{m}$. 


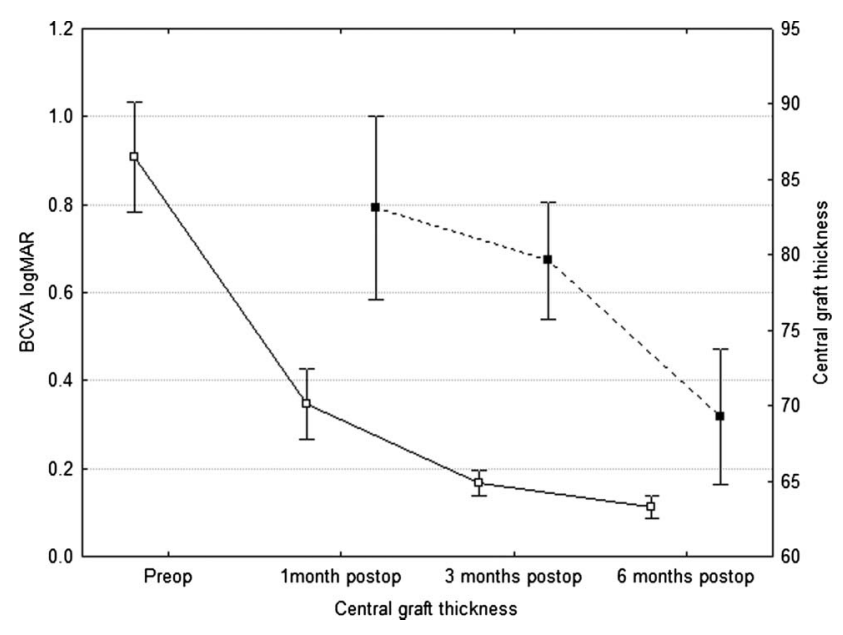

Figure 2 Improvement in best corrected visual acuity (BCVA) (logMAR) and reduction in mean central graft thickness $(\mu \mathrm{m})$ is observed during a 6-month follow-up.

$\left(\mathrm{F}_{(2,42)}=39.40 ; \mathrm{p}<0.001 ; \eta_{\mathrm{p}}^{2}=0.85\right)$ with statistically significant differences between donor ECD and ECD at 3 and 6 months (multiple comparisons; $\mathrm{p}=0.001$ and $\mathrm{p}<0.001$, respectively) while the ECD decline between 3 and 6 months was not significant $(\mathrm{p}=0.99)$.

In order to evaluate the influence of concomitant cataract surgery in terms of visual acuity, graft thickness and endothelial cell loss, we also compared patients undergoing only DSAEK with those having concurrent cataract surgery. In terms of visual acuity at 3 and 6 months, there were no statistically significant differences between the two groups (DSAEK group: $0.14 \pm 0.12 \log$ MAR and $0.11 \pm 0.09 \log$ MAR at 3 and 6 months vs the concurrent cataract surgery group: $0.16 \pm 0.06 \log \mathrm{MAR}$ and $0.14 \pm 0.06 \log \mathrm{MAR}$; independent samples $\mathrm{t}$ test: $\mathrm{p}=0.71$ and $\mathrm{p}=0.13$ at 3 and 6 months). There were no differences in central graft thickness (DSAEK group: $80.8 \pm 16.4 \mu \mathrm{m}(\mathrm{mean} \pm \mathrm{SD}$ ) and $70.0 \pm 17.4 \mu \mathrm{m}$ at 3 and 6 months vs the concurrent cataract surgery group: 76.8 \pm 9.8 and $68.3 \pm 9.7 \mu \mathrm{m} ; \mathrm{p}=0.66$ and $\mathrm{p}=0.86$ at 3 and 6 months). The same was true for peripheral graft thickness $(p=0.45$ and $\mathrm{p}=0.38$ at 3 and 6 months, respectively) and ECD ( $p=0.97$ and $\mathrm{p}=0.25$ at 3 and 6 months, respectively).

Grafts unfolded successfully in the anterior chamber in all surgeries. There were no graft detachments, pupillary blocks or primary graft failures.

\section{DISCUSSION}

The influence of endothelial graft thickness on visual acuity in DSAEK is controversial. ${ }^{7-10}{ }^{13}$ However, studies on this subject have focused either on relatively thick grafts $(160-170 \mu \mathrm{m})$ or on grafts prepared by manual dissection. ${ }^{8-10} 1314$ Assessment of grafts of less than $130 \mu \mathrm{m}$ shows a positive correlation between thickness and visual acuity, ${ }^{67}$ suggesting that an effect may exist under a certain thickness. Even though other factors may also influence visual acuity, such as the extension and duration of preoperative corneal oedema and the irregularity of the anterior cornea surface, graft thickness seems to be an important factor.

Few techniques for creating grafts thinner than $100 \mu \mathrm{m}$ have been presented. ${ }^{15-17}$ Therefore, to evaluate the influence of graft thickness on visual acuity we must have a technique that will consistently yield thin grafts.

The technique we describe in this paper involves performing a femtosecond laser first to prevent the variability of a double microkeratome cut and reduce the risk of perforation. Avoidance of a double femtosecond cut reduces the risk of a rough stromal bed and endothelial damage. ${ }^{18} 19$

Despite aiming for grafts of less than $100 \mu \mathrm{m}$, a target graft thickness figure of $110 \mu \mathrm{m}$ was used in the formula for safety reasons. Thus, approximately $410 \mu \mathrm{m}$ of corneal tissue is cut with a $300 \mu \mathrm{m}$ microkeratome head. Because the microkeratome we use usually cuts more than $300 \mu \mathrm{m},{ }^{20}$ we found that having $110 \mu \mathrm{m}$ as the target would actually yield grafts thinner than $100 \mu \mathrm{m}$ without perforation. Final graft thickness is obtained by programming the laser to cut at a customised depth for each cornea, depending on the initial pachymetry, in order to always leave the same thickness (approximately $410 \mu \mathrm{m}$ ) for the microkeratome cut. Accordingly, there was no correlation between initial donor thickness and graft thickness at any time point because the first cut essentially makes all corneas equal in terms of thickness. This avoids using nomograms and performing pachymetry between cuts, and means only one microkeratome head is needed, here a $300 \mu \mathrm{m}$ head, but other heads will probably give a good result as well. Since the microkeratome cut depth depends on several factors, such as intrachamber pressure, tissue thickness and manual rotation speed, these factors are kept as constant as possible to reduce variability. An important aspect of this technique is that the thinner cut is performed first, leaving a thick cornea for the microkeratome. Because the anterior stroma is more compact, this approach avoids irregular cuts and buttonholes during the microkeratome cut. ${ }^{21} \mathrm{~A}$ further advantage is that equipment already available in many cornea centres can be used. One limitation of this technique is that donor corneas of less than $500 \mu \mathrm{m}$ cannot be cut because the Intralase has a minimum ablation depth of $90 \mu \mathrm{m}$.

This new approach shows endothelial cell loss comparable with that reported for standard DSAEK and visual results similar to published DMEK results. ${ }^{82}{ }^{22-28}$ In general, endothelial cell loss can result from overmanipulation. However, we used the same DSAEK technique as we did previously with thick grafts; there were no complications, and the grafts unfolded successfully in the anterior chamber in all procedures. Moreover, it is also known that organ cultured corneas systematically carry non-viable endothelial cells that are implicated in

Table 2 Preoperative and postoperative best corrected visual acuity (CDVA in Snellen and logMAR) and spherical equivalent (D)

\begin{tabular}{llll}
\hline & Preoperative & 3 months & 6 months \\
\hline Snellen CDVA (logMAR mean \pm SD) & $20 / 160(0.91 \pm 0.58)^{*}$ & $20 / 30(0.15 \pm 0.09) \dagger$ & $20 / 25(0.11 \pm 0.07)$ \\
Spherical equivalent D $($ mean \pm SD) & $-1.31 \pm 2.5$ & $-1.06 \pm 1.75$ & $-0.7 \pm 0.92$ \\
ECD (cells/mm $)$ & 2675 (donor cells) $)$ & $1827 \pm 241 \S$ & $1729 \pm 296$ \\
\hline
\end{tabular}

Endothelial cell density (ECD) (cells/mm²) of the donor corneas, as supplied by the eye bank and mean ECD at 3 and 6 months postoperative.

*Statistically significant results between preoperative and 3 and 6 months ( $p=0.017$ and 0.013 ).

†No statistically significant differences between 3 and 6 months $(p=0.56)$.

¥Statistically significant differences between donor ECD and ECD at $3(p=0.001)$ and 6 months $(p<0.001)$.

$\S$ No statistically significant differences between 3 and 6 months $(p=0.99)$.

CDVA, corrected distance visual acuity. 
cell death and go undetected when trypan blue staining is used. ${ }^{29}$ There were no differences in terms of visual acuity, graft thickness and endothelial cell loss between patients undergoing DSAEK alone and those having concurrent cataract surgery. Concerning visual acuity, patients without concurrent cataract surgery were already pseudophakic, which could explain why no differences were found. Concerning graft thickness and endothelial cell loss, because cataract surgery is performed before Descemet stripping and graft insertion it is not likely to influence these parameters.

In conclusion, grafts of less than $100 \mu \mathrm{m}$ could be safely and consistently obtained. Although the initial results are very promising, further studies with larger patient cohorts and longer follow-up times are necessary. Studies should also clarify the ideal graft thickness for DSAEK, in terms of both visual recovery and endothelial cell loss.

Acknowledgements We thank Robert Van Velze for his help on setting the parameters of this study.

Contributors AMR, conception and design, analysis and interpretation of data, manuscript writing; MJQ, EC and IMIPM, analysis and interpretation of data; MFS, manuscript writing and revising it critically for important intellectual content; JNM, conception and design, manuscript revision and approval of the version to be published.

\section{Competing interests None.}

Patient consent Obtained.

Ethics approval Ethics approval was obtained from the local ethics board.

Provenance and peer review Not commissioned; externally peer reviewed.

\section{REFERENCES}

1 Lee WB, Jacobs DS, Musch DC, et al. Descemet's stripping endothelial keratoplasty: safety and outcomes: a report by the American Academy of Ophthalmology. Ophthalmology 2009;116:1818-30.

2 Price MO, Price FW Jr. Descemet's stripping with endothelial keratoplasty: comparative outcomes with microkeratome-dissected and manually dissected donor tissue. Ophthalmology 2006;113:1936-42.

3 Gorovoy MS. Descemet-stripping automated endothelial keratoplasty. Cornea 2006:25:886-9.

4 Chen ES, Terry MA, Shamie N, et al. Descemet-stripping automated endothelial keratoplasty: six-month results in a prospective study of 100 eyes. Cornea 2008;27:514-20.

5 Ham L, Dapena I, van der Wees J, et al. Secondary DMEK for poor visual outcome after DSEK: donor posterior stroma may limit visual acuity in endothelial keratoplasty. Cornea 2010;29:1278-83.

6 Pogorelov P, Cursiefen C, Bachmann BO, et al. Changes in donor corneal lenticule thickness after Descemet's stripping automated endothelial keratoplasty (DSAEK) with organ-cultured corneas. Br I Ophthalmol 2009:93:825-9.

7 Neff KD, Biber JM, Holland EJ. Comparison of central corneal graft thickness to visual acuity outcomes in endothelial keratoplasty. Cornea 2011;30:388-91.

8 Van Cleynenbreugel H, Remeijer L, Hillenaar T. Descemet stripping automated endothelial keratoplasty: effect of intraoperative lenticule thickness on visual outcome and endothelial cell density. Cornea 2011;30:1195-200.
9 Seery LS, Nau CB, McLaren JW, et al. Graft thickness, graft folds, and aberrations after descemet stripping endothelial keratoplasty for fuchs dystrophy. $\mathrm{Am} J$ Ophthalmol 2011;152:910-16.

10 Ahmed KA, McLaren JW, Baratz KH, et al. Host and graft thickness after Descemet stripping endothelial keratoplasty for Fuchs endothelial dystrophy. Am J Ophthalmol 2010;150:490-7 e2.

11 van der Meulen IJ, Patel SV, Lapid-Gortzak R, et al. Quality of vision in patients with fuchs endothelial dystrophy and after descemet stripping endothelial keratoplasty. Arch Ophthalmol 2011;129:1537-42.

12 Busin M, Bhatt PR, Scorcia V. A modified technique for descemet membrane stripping automated endothelial keratoplasty to minimize endothelial cell loss. Arch Ophthalmol 2008;126:1133-7.

13 Shinton AJ, Tsatsos M, Konstantopoulos A, et al. Impact of graft thickness on visual acuity after Descemet's stripping endothelial keratoplasty. Br J Ophthalmol 2012;96:246-9.

14 Nieuwendaal $\mathrm{CP}$, van Velthoven ME, Biallosterski C, et al. Thickness measurements of donor posterior disks after descemet stripping endothelial keratoplasty with anterior segment optical coherence tomography. Cornea 2009;28:298-303.

15 Busin M, Patel AK, Scorcia V, et al. Microkeratome-Assisted Preparation of Ultra-thin Grafts for Descemet stripping automated endothelial keratoplasty (DSAEK). Invest Ophthalmol Vis Sci 2012;53:521-4.

16 Sikder S, Nordgren RN, Neravetla SR, et al. Ultra-thin donor tissue preparation for endothelial keratoplasty with a double-pass microkeratome. Am I Ophthalmol 2011;152:202-8 e2.

17 Hiortdal J, Nielsen E, Vestergaard A, et al. Inverse cutting of posterior lamellar corneal grafts by a femtosecond laser. Open Ophthalmol J 2012;6:19-22.

18 Rosa AM, Neto Murta J, Quadrado MJ, et al. Femtosecond laser versus mechanical microkeratomes for flap creation in laser in situ keratomileusis and effect of postoperative measurement interval on estimated femtosecond flap thickness. J Cataract Refract Surg 2009;35:833-8.

19 Cheng YY, Hendrikse F, Pels E, et al. Preliminary results of femtosecond laser-assisted descemet stripping endothelial keratoplasty. Arch Ophthalmol 2008;126:1351-6.

20 Kelliher C, Engler C, Speck C, et al. A comprehensive analysis of eye bank-prepared posterior lamellar corneal tissue for use in endothelial keratoplasty. Cornea 2009;28:966-70.

21 Hamilton DR, Johnson RD, Lee $\mathrm{N}$, et al. Differences in the corneal biomechanical effects of surface ablation compared with laser in situ keratomileusis using a microkeratome or femtosecond laser. J Cataract Refract Surg 2008:34:2049-56.

22 Tourtas T, Laaser K, Bachmann BO, et al. Descemet membrane endothelial keratoplasty versus descemet stripping automated endothelial keratoplasty. Am J Ophthalmol 2012;153:1082-90 e2.

23 Li JY, Terry MA, Goshe J, et al. Three-Year Visual Acuity Outcomes after Descemet's Stripping Automated Endothelial Keratoplasty. Ophthalmology 2012;119:1126-9.

24 Ratanasit A, Gorovoy MS. Long-term results of Descemet stripping automated endothelial keratoplasty. Cornea 2011:30:1414-18.

25 Terry MA. Endothelial keratoplasty: a comparison of complication rates and endothelial survival between precut tissue and surgeon-cut tissue by a single DSAEK surgeon. Trans Am Ophthalmol Soc 2009;107:184-91.

26 Price MO, Gorovoy M, Benetz BA, et al. Descemet's stripping automated endothelial keratoplasty outcomes compared with penetrating keratoplasty from the Cornea Donor Study. Ophthalmology 2010;117:438-44.

27 Terry MA, Chen ES, Shamie N, et al. Endothelial cell loss after Descemet's stripping endothelial keratoplasty in a large prospective series. Ophthalmology 2008;115:488-96 e3.

28 Anijeet DR, Rachdan D, Shah S. Visual improvement after corneal endothelial transplantation: are we seeing better? Br J Ophthalmol 2012;96:309-10.

29 Gain $\mathrm{P}$, Thuret $\mathrm{G}$, Chiquet $\mathrm{C}$, et al. Value of two mortality assessment techniques for organ cultured corneal endothelium: trypan blue versus TUNEL technique. $\mathrm{Br}\rfloor$ Ophthalmol 2002;86:306-10. 